\title{
The Effect of Coresidence on Parental Health in Japan
}

\author{
Shiko Maruyama*,† \\ University of Technology Sydney
}

December 5, 2014

\begin{abstract}
The empirical evidence of the effect of intergenerational coresidence by elderly parents and their adult children on parental health remains inconclusive. This study provides a new estimate of the coresidence effect by addressing non-random selection and heterogeneity in the treatment effect. Examination of Japanese data reveals: (i) an insignificant, negative average coresidence effect; (ii) a significant, negative coresidence effect on the treated; and (iii) that parents with unmet care needs and limited resources, typically widowed, disabled mothers, are most likely to suffer from a significant, negative coresidence effect. The results support the theory that coresidence may worsen elderly parents' health because care burdens on their adult children create disincentives for the parents to invest in longevity. The significant heterogeneity
\end{abstract}

*Address correspondence to: Shiko Maruyama, Economics Discipline Group, University of Technology Sydney, PO Box 123, Broadway, NSW 2007, Australia. Phone: +61 29514 7730. E-mail: shiko.maruyama@uts.edu.au.

†The author gratefully acknowledges financial support from the Australian Research Council's Discovery Projects funding scheme (project number DP110100773). Helpful comments from Elena Capatina, Denise Doiron, Hajime Katayama, and Kevin Lang are gratefully acknowledged. I also thank the Nihon University Center for Information Networking for the use of the Nihon University Japanese Longitudinal Study of Aging data. 
in the coresidence effect suggests potential scope for a better-targeted long-term care program.

\section{Introduction}

According to the theory of health capital, individuals make health-related decisions taking their consequences into consideration. The expected marginal costs and benefits of health investments determine the optimal trajectory of one's future health and thereby determine one's demand for longevity (Grossman, 1972; Ehrlich and Chuma, 1990). Various sources of benefits and costs of health investments have been discussed in the literature, but the presence of family members has rarely received attention. If elderly parents are altruistic toward their adult children, how does the presence of the latter affect the parents' healthrelated decisions and demand for longevity? What if the parents have significant health-care needs?

Intergenerational coresidence by elderly parents and their adult children is often formed to meet parental care needs and to provide family support for security in old age. It is difficult to cast doubt on the positive, vital role of coresidence with children. In aging societies, care and attention provided by adult children remains an important source of support in old age. While the demand for elderly care is growing at an unprecedented rate, around $80 \%$ of the hours of care are provided informally, with children providing $41 \%$ of all informal care in the U.S., $43 \%$ in the U.K., and $60 \%$ in Japan (OECD, 2005). In Japan, informal care provided by children often coincides with parent-child coresidence (The Ministry of Health, Labour and Welfare, 2008). However, despite the fact that the importance of informal care is widely recognized, despite the widespread notion that coresiding children are caregivers 
who provide comprehensive assistance to elderly parents, and despite numerous studies of the coresidence effect by researchers in the fields of sociology, demography, and gerontology, the empirical literature has yet to reach a consensus on the causal effect of coresidence with an adult child on parental health.

A better understanding of the coresidence effect has important implications for agedcare policies. As aging societies are pushing a growing number of frail old individuals into needing care, securing quality aged care has become a priority for governments. Given that care and attention provided by adult children still plays a major role, long-term care policies need to develop a well-balanced, effective use of formal and informal care. For example, Japan, facing the world's fastest population aging, established the Long-Term Care Insurance in 2000, with a policy objective, "Socialization of Care", that intends to develop various formal care services and release women from the burden of caregiving. On the other hand, many other countries have programs that support family caregivers such as respite care (OECD, 2013). To assist evidence-based policy decisions, there exist many reliable evidences on the "costs and benefits" of formal and informal care, except for the "benefit" of informal care. The burden of informal caregiving borne by carers is widely documented. Caregiving may significantly affect their labor-supply decisions (Ettner, 1995; Carmichael et al., 2010; Heitmueller, 2007; Sugawara and Nakamura, 2014) and their quality of life (Fast et al., 1999; Hall et al., 2014; Kenny et al., 2010). Research on the quality measurement of formal care is also developing significantly (OECD, 2013). Thus the solid evidence of the effectiveness of informal care is an important remaining element necessary to enhance aged-care programs.

Two questions are posed in this study. First, is the coresidence effect indeed posi- 
tive? The literature on the coresidence effect has so far paid limited attention to the non-experimental nature of data, and this may account for the mixed results. This study aims to provide a rigorous causal estimate by capitalizing on the program evaluation literature. In my setup, coresidence by an elderly parent and an adult child is referred to as the "treatment." The treatment group consists of elderly parents who live with an adult child and the control group consists of elderly parents who do not coreside with an adult child.

Second, how do we explain the sign of the coresidence effect? Since one important reason for coresidence is certainly to meet a parent's care needs, one would expect to find incontrovertible evidence of its positive effect in the literature. In this study, I propose a theory of health transfer as to why intergenerational coresidence may affect parental health negatively, and test predictions derived from the theory utilizing a structural econometric model. I argue that coresidence may cause parents with serious care needs to be concerned that prolonging their own lives means placing an additional burden on their adult children. This concern creates disincentives to invest in their health. For parents without serious care needs, on the other hand, coresidence creates incentives to remain healthy and thus delay the onset of potential caregiving burdens on coresiding children. This theory thus predicts a negative relationship between parents' care needs and the coresidence effect.

Two econometric issues may have biased the results of previous studies. First, there may exist non-random selection into coresidence, especially selection by unobservable factors: that is, the possibility that the treated group is systematically different from the control group, even after observable characteristics are controlled for. For instance, suppose that sociable parents are more likely to coreside with children than unsociable ones. If an econometrician does not observe their sociability and if sociability contributes to future health, 
the estimate of coresidence effect suffers from upward bias. This potential bias has been largely overlooked in the existing literature. Second, given the considerable heterogeneity in the motives and behavior of families, it is reasonable to suspect that the coresidence effect would vary with various observable and unobservable family characteristics. Suppose that different families experience different coresidence effects but the distribution of the coresidence effect centers around zero. Then the resulting overall effect averages zero, and, without a heterogeneous treatment effect framework, an econometrician will incorrectly conclude that coresidence has no effect. To address non-random selection into coresidence and heterogeneity in the coresidence effect, I employ a factor structure model.

I use the Nihon University Japanese Longitudinal Study of Aging (NUJLSOA), a nationally representative panel survey of elderly Japanese. Japanese culture, which features the close family ties found throughout East Asian societies, maintains one of the highest intergenerational coresidence rates among developed countries, thus providing an ideal setting for this study. The population in the analysis consists of elderly Japanese who have at least one adult child in the base year, 2003. The dependent variable is the parent's health outcome three years later constructed from the mortality status and a self-assessed health score. This combination of mortality and self-reported health allows me to fully exploit information in these two variables and avoid truncation and attrition bias due to death. I use the parent's region of residence (rural or not), the land price in the region of residence, and whether the parent lived in a rural area in childhood as instruments to address the issue of non-random selection into coresidence, arguing that these are valid instruments for the time period under consideration.

The main results are as follows. First, the point estimate of the average treatment 
effect of coresidence on the three-year survival rate is -0.0184 with a standard error of 0.0133. If coresidence is randomly assigned, the three-year survival rate of elderly parents decreases by 1.84 percentage points on average. Although the estimate is not statistically significant, the effect is not greater than +1.0 percentage points at the $95 \%$ confidence level; thus there is no evidence of a positive coresidence effect. Second, the estimated average treatment effect on the treated is statistically significant, negative, and substantial. The three year survival rate of elderly parents in coresidence would be 5.32 percentage points higher (1.75 percentage point per annum) if they lived independently. Third, the results are consistent with the theory of health transfer: all else being equal, the coresidence effect is negatively associated with coresidence burdens. Vulnerable parents with serious care needs but without the means to make financial compensation, typically mothers who are widowed and disabled, are most likely to be in coresidence and suffer from a substantial negative coresidence effect. The significant heterogeneity in the coresidence effect even after the introduction of the Long-Term Care Insurance suggests potential scope for a better targeted long-term care program in Japan.

\section{Mixed Findings on the Effect of Coresidence}

Researchers in different fields have studied the effect of living arrangements on the health of the elderly. These studies cover both Western and Asian countries and look at various populations and various health outcomes. Most of the studies undertaken prior to the year of 2000 rely on a cross-sectional approach, and hence suffer from potential reverse causation

— the possibility that coresidence occurs in response to declining parental health. Recently, the use of panel data has become standard. Table 1 summarizes recent studies as well as 
some early panel studies. Their findings are mixed and it is difficult to draw a general conclusion. For example, Li et al. (2009) study the oldest old in China and find that whereas having a spouse in the household provides the best health protection, the effect of living with adult children is mixed. Similar results are found for the mental health of elderly parents in Singapore (Chan et al., 2011). Using data from Israel, Walter-Ginzburg et al. (2002) find that elderly parents who live with a child have a higher mortality risk than those living alone. In Japan, the risk of heart disease among elderly mothers who coreside with children is twice as high as the risk for those who do not (Ikeda et al., 2009), and those elderly parents cared for by daughters are found to have a higher mortality rate than those cared for by a spouse (Nishi et al., 2010).

To the best of my knowledge, Do and Malhotra (2012) and Johar and Maruyama (2014) are the only studies that attempt to correct for non-random selection into coresidence. Do and Malhotra (2012) use the number of sons as an instrument, arguing that the instrument is related to traditional rules of coresidence and should not directly affect parental health in the Korean setting. They find that living with a child reduces depressive symptoms among South Korean widowed elderly mothers. Johar and Maruyama (2014) apply the econometric model presented in this study to parents 60 years of age and older in Indonesia. Using community level traditions and customs as instruments, they find a significant, negative coresidence effect on the treated.

[Insert Table 1] 


\section{Empirical Model}

\subsection{Latent Health Model with Heterogeneous Treatment Effects}

To estimate the coresidence effect and address non-random selection and heterogeneity in the coresidence effect, I extend the factor-structure framework of Aakvik, Heckman, and Vytlacil (2005) (henceforth AHV), which provides a flexible yet parsimonious and tractable specification that yields easily interpretable expressions for treatment parameters. The original AHV model simultaneously estimates three binary equations, for (1) selection, (2) treated outcomes, and (3) untreated outcomes. Because the identification of a model with three binary equations is generally challenging, I extend the original binary-outcome model by allowing for an ordered categorical outcome, in which the main dependent variable is a combination of the three-year survival outcome and, in case of survival, five-categorical health status after three years. This extension allows me to fully utilize the health-status information in data to further aid identification and to stabilize the estimation procedure, requiring no strong assumptions. For further details regarding the model assumptions, identification, and estimation procedure, see Johar and Maruyama (2014).

The treatment group comprises elderly parents who live with a child, and the control group comprises elderly parents who do not live with a child. For each elderly parent $i$, let a binary construct, $D_{i}$, be the treatment status: 1 for coresidence with a child and 0 otherwise. For each parent $i$, define two potential outcomes $\left(Y_{0 i}, Y_{1 i}\right)$ corresponding to the health outcomes after three years in the non-coresidence and coresidence states, respectively. $Y_{0 i}$ and $Y_{1 i}$ measure subjective health and take six possible values: 5 for very healthy, 4 for healthy, 3 for average, 2 for poor, 1 for very poor, and 0 for death. Parent $i$ 
may be married, but only one parent from each household is included in the analysis, and $Y_{0 i}$ and $Y_{1 i}$ are assumed to be independent across observations.

Because all dependent variables are discrete, a latent-index framework is used. The coresidence equation is specified as

$$
\begin{aligned}
& D_{i}^{*}=Z_{i} \beta_{D}-U_{D i}, \\
& D_{i}=1 \text { if } D_{i}^{*} \geq 0, D_{i}=0 \text { otherwise, }
\end{aligned}
$$

where $Z_{i}$ is a vector of observed characteristics (including the baseline health) that influence the family's coresidence decision, $\beta_{D}$ is a vector of associated parameters, and $U_{D i}$ captures unobserved costs of coresidence. The latent variable, $D_{i}^{*}$, measures the net utility of coresidence.

The health outcomes, $Y_{j i}, j=0,1$, are specified as follows:

$$
Y_{j i}^{*}=X_{i} \beta_{j}-U_{j i}, \quad Y_{j i}=\left\{\begin{array}{l}
5 \text { if } Y_{j i}^{*} \geq c_{4}, \\
k \text { if } c_{k}>Y_{j i}^{*} \geq c_{k-1}, \quad k=4,3,2, \\
1 \text { if } c_{1}>Y_{j i}^{*} \geq 0, \\
0 \text { if } 0>Y_{j i}^{*},
\end{array}\right.
$$

where $X_{i}$ is a vector of observed baseline characteristics, $\beta_{j}$ denotes its associated parameters, $U_{j i}$ is an error term that captures unobserved health shocks, and $c_{1}, c_{2}, c_{3}$, and $c_{4}$ are cutoff parameters. The exclusion restriction is satisfied when $X_{i} \subset Z_{i}$. The latent health variable, $Y_{j i}^{*}$, has a structural interpretation: if it is positive, parent $i$ survives, and a larger value indicates better health. As described in the next section, $X_{i}$ includes the baseline 
health information. Thus, what the model explains is not the health status per se but effectively how health changes over the three-year time window. The cutoff points determine the category into which parent $i$ 's health falls. This extension of the original AHV model requires only two more reasonable assumptions: (1) death is worse than the worst health status; $^{1}$ and (2) the cutoff parameters are the same across individuals and across treated and untreated states. Because $X_{i}$ contains a constant term, setting the lowest cutoff to zero does not impose a restriction.

Following AHV, the error terms in equations (1) and (2) are assumed to be governed by the following normal factor structure:

$$
U_{D i}=-\theta_{i}+\varepsilon_{D i}, U_{0 i}=-\alpha_{0} \theta_{i}+\varepsilon_{0 i}, \text { and } U_{1 i}=-\alpha_{1} \theta_{i}+\varepsilon_{1 i},
$$

where each of $\theta, \varepsilon_{D}, \varepsilon_{0}$, and $\varepsilon_{1}$ follows the i.i.d. standard normal. ${ }^{2}$ This specification implies

$$
\operatorname{Cov}\left(U_{D}, U_{0}\right)=\alpha_{0}, \operatorname{Cov}\left(U_{D}, U_{1}\right)=\alpha_{1}, \text { and } \operatorname{Cov}\left(U_{0}, U_{1}\right)=\alpha_{0} \alpha_{1}
$$

Estimation relies on the maximum-likelihood method. The likelihood function has the form

$$
L=\prod_{i=1}^{N} \int \operatorname{Pr}\left(D_{i}, Y_{i} \mid X_{i}, Z_{i}, \theta\right) \phi(\theta) d \theta
$$

where $Y_{i} \equiv\left(1-D_{i}\right) Y_{0 i}+D_{i} Y_{1 i}$ and $\phi$ denotes the standard-normal probability density

\footnotetext{
${ }^{1}$ This is a standard assumption in the health economics literature (e.g., standard health capital models and the QALY-weights literature). Moreover, besides mortality, subjective health is the most commonly used measure of individual health in the literature (Banks and Smith, 2011) and has been found to be strongly correlated with life expectancy and the prevalence of chronic diseases.

${ }^{2}$ The i.i.d. normality assumption guarantees the following standard assumptions: (i) $\left(U_{D}, U_{0}\right)$ and $\left(U_{D}, U_{1}\right)$ are independent of $(Z, X)$, (ii) $Y_{0}$ and $Y_{1}$ have finite first moments, and (iii) $1>\operatorname{Pr}(D=1 \mid X)>0$.
} 
function. To integrate $\theta_{i}$, numerical approximation by Gauss-Hermite quadrature is used.

\subsection{Treatment Parameters}

An advantage of the factor structure model is that the average treatment parameters and the distributions of the treatment parameters can be obtained from the estimated structural parameters. Let $\Delta$ denote the treatment effect with regard to survival for a given parent: $\Delta=I\left[Y_{1} \geq 1\right]-I\left[Y_{0} \geq 1\right]$. Note that $\Delta$ includes a counterfactual and is not observed for each individual. The parameters of interests are: (i) the average treatment effect $(A T E)$; (ii) the average treatment effects on the treated (ATT) and on the untreated $(A T U)$; and (iii) the marginal effect of covariate $X_{k}$ on the ATE. Parameters (i)-(ii) measure the average value of $\Delta$ on different conditioning sets. The $A T E$ is the average effect of coresidence for a parent chosen at random from the population. The $A T E$ given a value of $X$ is defined as

$$
\Delta^{A T E}(x) \equiv E(\Delta \mid X=x)
$$

The ATT and ATU measure the average effects for a parent who is in coresidence and for a parent who is not in coresidence, respectively, and are defined as

$$
\begin{aligned}
& \Delta^{A T T}(x, z, D=1) \equiv E(\Delta \mid X=x, Z=z, D=1)=E\left(\Delta \mid X=x, U_{D} \leq z \beta_{D}\right), \\
& \Delta^{A T U}(x, z, D=0) \equiv E(\Delta \mid X=x, Z=z, D=0)=E\left(\Delta \mid X=x, U_{D}>z \beta_{D}\right) .
\end{aligned}
$$

The ATT is the parameter most commonly estimated in literature. The marginal effect of observed characteristics on the $A T E$, (iii), tells us how the coresidence effect varies across observed characteristics. It is informative in inferring the mechanism underlying the causal 
effect.

To obtain the estimates of these (unconditional) treatment parameters, I integrate estimated treatment parameters against the empirical distribution of $X$ and $Z$. Standard errors are computed using the delta method. Table 1 in Johar and Maruyama (2014) provides the summary of these treatment parameters.

\section{Data}

The data are derived from the Nihon University Japanese Longitudinal Study of Aging (NUJLSOA), a nationally representative survey of the population 65 years of age and older. ${ }^{3}$ The analyses in this study use the latest two waves: the third and fourth waves, conducted in 2003 and 2006, respectively. ${ }^{4}$ The 2006 wave is used only to construct the health outcomes, and the 2003 wave provides all the other information necessary to select our sample and generate the other variables. The population of interest consists of elderly parents: individuals 65 years of age and older who have at least one child in the base year, 2003. The definition of a child in this study includes biological, step, and adopted children but not children-in-law. The unit of observation is an elderly parent who has completed the third-wave survey. In the NUJLSOA, if the subject is incapable of being interviewed on account of illness, dementia, or another cause, the interview may be conducted with a proxy. The sample does not include the spouses of interviewees. I exclude elderly parents who are in hospitals or institutions in the base year, who live with persons other than their spouse and child's family, or who live with multiple children. The proportion of observations

\footnotetext{
${ }^{3}$ For the details of the NUJLSOA, see http://www.usc.edu/dept/gero/CBPH/nujlsoa/.

${ }^{4}$ The fact that the time intervals between the earlier waves are shorter makes them less suitable for analyzing effects on the mortality rate.
} 
excluded for these restrictions is less than $10 \%$. Having also excluded observations with data problems, such as missing values and inconsistent answers, I have a final sample consisting of 3,023 elderly parents. Of these parents, $1,572(52.0 \%)$ lived with a child in the base year.

[Insert Table 2]

Table 2 defines the variables used in this study. The dependent variable, $Y_{i} \equiv\left(1-D_{i}\right) Y_{0 i}+$ $D_{i} Y_{1 i}$, is a six-category health outcome that takes the value zero if an elderly parent dies within three years (between 2003 and 2006). If the parent survives, it takes a value between 1 and 5 according to the five self-assessed health levels in 2006. Table 3 shows the distribution of the health outcome. The distribution centers around "3: Average" with a significant mass in the death category. The three-year mortality rate is 10.0 percent in the sample, or 3.23 percent per annum. ${ }^{5}$ Comparison of the distributions of the non-coresidence and coresidence groups shows that coresidence is associated with a lower survival rate. Such negative association can be observed if parents with worse health conditions are more likely to be in coresidence. The bottom half of Table 3 shows a moderate negative association between the baseline health and coresidence, indicating the importance of controlling for the baseline health.

[Insert Table 3]

Table 4 provides descriptive statistics for the other variables used in this study. Variables from Spouse to Community activity are individual-level characteristics of each survey

\footnotetext{
${ }^{5}$ This number is consistent with the vital statistics of the Japanese: the national mortality rate of the elderly (65 and over) in 2005, including hospitalized and institutionalized individuals, was 3.46 percent per annum.
} 
respondent. The other variables in Table 4 are defined for each elderly couple instead of each individual respondent, if the respondent is married. The variable, ADL Disability, is constructed as the first factor from a factor analysis of seven basic activities-of-dailyliving (ADL) items based on the 3,023 parent observations. Its mean value and standard deviation are roughly zero and one, respectively, and it takes a larger value when a parent is more severely disabled. All three child variables used in this study are defined at the parent level. We do not use the information on each child because our empirical framework abstracts the choice of which child to live with. Modeling multiple treatments makes the identification of causal effect infeasible.

[Insert Table 4]

The last three variables, Rural, Land price, and Origin rural, are the instrumental variables (IVs) used to address non-random selection into coresidence. The land price is constructed from a government source as an average price of residential properties sampled in each municipal area. The logic behind these IVs is that the regional background and the rurality and average land prices of current location are not likely to directly affect the health outcome of elderly parents when other covariates are held constant, but they do affect the coresidence decision by changing preferences over coresidence and the setup and maintenance costs of coresidence. The last three rows in Table 4 show that compared with parents living without children, parents living with a child are more likely to be from the countryside and currently in rural areas with lower land prices. As can be seen below, these IVs are indeed strongly correlated with coresidence. In cities with high land prices, intergenerational coresidence appears expensive to set up and maintain, perhaps requiring 
a larger house. ${ }^{6}$

At the same time, it is also reasonable to assume the exogeneity of my IVs in the Japanese context. Certainly those who live in urban areas and rural areas are likely to be different, e.g., in terms of income, education, and lifestyle; likewise, those with a rural background and those without a rural background may be systematically different; and land prices may reflect how livable those areas are. Through these channels my IVs are likely to be correlated with health outcomes unconditionally in the long run. However, the exogeneity condition necessary in this study is that when controlling for the base-year health and other observable characteristics, the IVs are unrelated to the three-year health outcome. All else being equal, it is unlikely that the location choice and the regional background make a significant difference to the three-year mortality. Providing further support for this argument is the fact that universal access to healthcare services is virtually guaranteed in Japan; elderly individuals are enrolled in the public health insurance and long-term-care insurance, which provide coverage to the elderly at a modest fee. Although the accessibility issue exists in some remote areas (e.g., remote islands), such remote and sparsely populated areas are not included in the data. One might also argue that the land price reflects the lifetime earnings and other unobserved attributes of the elderly who live in that area. However, this relationship is weak for this generation in Japan. The variance in land prices rose dramatically in the 1980s, providing some landowners with huge windfall capital gains. As a result, although current land prices indicate the cost of starting and maintaining coresidence, they are far less correlated with the prices at which

\footnotetext{
${ }^{6}$ If cultural tendency for coresidence affects the real-estate market at the municipality level, the reverse causation raises a concern about the validity of the land-price instrument. However, this seems not to be a concern in Japan because as discussed below, the major part of the land-price dispersion emerged in the last several decades of the 20th century, whereas social norms and traditions evolve much more slowly.
} 
these individuals purchased their land. Similarly, one may argue that a correlation between the time trends in health and land prices may exist even when baseline health is controlled for and thus may affect the validity of the instrument, but in Japan this will not be a major concern for the same reason. In addition, I conduct several statistical tests, and, as shown in the next section, the results confirm the appropriateness of my instruments.

\section{Results}

\subsection{Linear Regressions and Instrument Validity}

Before reporting the results of the full structural model, I discuss results from simple linear models to highlight the nature of the data. Table 5 reports three simple estimates of the coresidence effect: (1) the unconditional average effect; (2) the average effect from a linear probability model (LPM); and (3) the average effect from an LPM with the IVs. The unconditional average effect shows that the three-year mortality rate for parents in coresidence is 3.6 percentage points higher than it is for those who have a child but live independently. This difference is statistically significant at the 1 percent level. This estimate, however, may capture the systematic difference between the two groups rather than causal coresidence effect. In the LPM model in the next column, baseline covariates allow us to control for the observable differences between the two groups. The IV-LPM model in the last column controls for selection on both observables and unobservables. In neither model is the estimate of the coresidence effect statistically significant.

[Insert Table 5] 
A number of tests confirm the appropriateness of the instruments. First, in the firststage regression of the IV-LPM model in Table 5 , the three IVs are jointly significant, each with a $t$-statistic of $3.37,-2.38$, and 3.05 , respectively. They are thus strong predictors of coresidence. Second, the overidentification test supports the validity of the IVs: the $P$-value of the test based on the Hansen $J$-statistic is $0.675 .^{7}$ The validity of the IVs can also be tested by a "placebo test" in which I regress the three-year survival rate on the IVs and the same covariates used in the main analysis using childless elderly individuals. If intergenerational coresidence is the only channel through which the IVs potentially affect health outcomes, the IVs must have no significance in the health-outcome regression for those who do not have children. Table 6 reports the results of this placebo test based on an LPM on three-year survival and an ordered probit model for the six-category health outcome. Rural and Origin rural have no power to explain the two dependent variables and the effect of land price is weak and statistically insignificant. Lastly, in the above IVLPM model, my IVs pass a standard weak identification test: the Kleibergen-Paap Wald $F$-statistic is 16.02, and the Stock-Yogo critical value of the weak IV test for $10 \%$ maximal LIML size is 6.46 (Stock and Yogo, 2005). These tests indicate the relevance, validity, and power of the instruments.

[Insert Table 6]

\subsection{Estimated Coefficients}

The full model estimates the coresidence equation, (1), and the two health-outcome equations, (2), simultaneously. Table 7 reports the coefficient estimates of the coresidence equa-

\footnotetext{
${ }^{7}$ Since the dependent variable is binary, I report statistics robust to heteroskedasticity.
} 
tion, and Table 8 reports the coefficient estimates of the two health-outcome equations for the non-coresidence and coresidence states.

The results of the coresidence equation confirm the presence of non-random selection into coresidence. A parent is more likely to be in coresidence with a child if the parent is affected by conditions that require family support, such as widowhood, limitations in daily activities, and dementia, whereas the results also show that parents with poor health and low subjective happiness are less likely to be in coresidence. Parents are also more likely to coreside with a child when they are working, less educated, and a parent of more children. Parents who own a house are less likely to be in coresidence. This is inconsistent with common findings in the literature (Maruyama and Johar, 2013), probably reflecting inter vivos transfer frequently observed in Japan: house ownership is often transferred to a child in coresidence rather early and houses for coresidence are often purchased with substantial financial assistance from parents (Tabuchi, 2008; Johar et al., 2014). Interpretation of the coefficient estimates in the coresidence equation, however, requires caution because this equation does not address unobserved heterogeneity and therefore captures only statistical association rather than causal relationship. The results also confirm the significance of the instruments. Living in an urban area with a higher land price is associated with higher costs of coresidence, which significantly reduces the probability of coresidence. The rural background, on the other hand, increases the probability of coresidence. This significance of the IVs in the selection equation contrasts with their weak explanatory power in the "placebo" regression for childless elderly individuals (Table 6).

[Insert Table 7]

The results of the two health-outcome equations are reported in Table 8. Although some 
coefficients vary considerably between the two health equations, many estimated coefficients are consistent between the two equations and show expected signs. Parents who have better health outcomes after three years tend to be younger parents with a job, better base-period health, and a higher level of subjective happiness. Better health outcomes are also expected for those who manifest fewer symptoms of depression and are more involved in community activities. The table also reports the estimates of four cutoff points for the five discrete subjective-health outcomes $\left(c_{1}, c_{2}, c_{3}, c_{4}\right)$. These thresholds are relative to the threshold for death, normalized at 0 .

The factor structure parameter, $\theta$, enters the health outcome equations with the coefficient parameters, $\alpha_{0}$ and $\alpha_{1}$. Note that a model with no selection on unobservables implies $\alpha_{0}=\alpha_{1}=0$. As shown in the first row in Table 8 , the estimates of $\alpha_{0}$ and $\alpha_{1}$ are statistically significant at the $1 \%$ confidence level. Thus the null hypothesis of no selection bias due to unobservables is rejected and the reported one-factor model is the preferred specification.

[Insert Table 8]

\subsection{Treatment Parameters and Selection on Unobservables}

The estimated treatment parameters are reported in Table 9. The ATE is estimated to be -0.0184 , implying that if coresidence with a child is randomly assigned to elderly parents, the three-year mortality rate increases by 1.84 percentage points on average. The standard error of 0.013 indicates that although the $A T E$ estimate is not statistically significant, the effect is not greater than +1.0 percent at the $95 \%$ confidence level; intergenerational coresidence is therefore unlikely to have a substantial positive effect. The next three rows in 
Table 9 show distributional parameters of the ATE. I compute the distributional parameter, $\operatorname{Pr}(\Delta=1 \mid X) \equiv \operatorname{Pr}\left(Y_{1} \geq 1, Y_{0}=0 \mid x\right) . \operatorname{Pr}(\Delta=0 \mid X)$ and $\operatorname{Pr}(\Delta=-1 \mid X)$ are defined in the same manner. The results reveal that if coresidence were randomly assigned to elderly parents, $89.9 \%$ would not be affected by coresidence, $4.1 \%$ would avoid death because of coresidence, and $6.0 \%$ would die because of coresidence.

[Insert Table 9]

This picture changes radically when we look at the treatment effect on the treated. The ATT is estimated to be -0.0532 and is significant at the 1 percent level. This estimate implies that if parents in coresidence had not lived with children, their three-year survival rate would have been 5.32 percentage points higher (or 1.75 percentage points per annum). Thus families with a potentially negative coresidence effect tend to self-select into coresidence. Reflecting the heterogeneity in the coresidence effect, the $A T U$ is estimated to be 0.0349 .

\subsection{Robustness of Results}

In Table 10 I compare ATEs estimated by different specifications: (1) the unconditional average coresidence effect; (2) an LPM, in which I impose a constant treatment effect assuming no selection on unobservables; (3) an IV-LPM that allows selection on unobservables; (4) a binary probit model that assumes heterogeneity in the treatment effect and no selection on unobservables; (5) a binary factor structure model that assumes heterogeneity in the treatment effect and selection on unobservables; (6) an ordered probit model that assumes heterogeneity in the treatment effect and no selection on unobservables; and (7) an ordered factor structure model that assumes heterogeneity in the treatment effect and 
selection on unobservables (the preferred full model). The results show that addressing non-random selection on unobservables leads to greater negative treatment effects, indicating positive selection on unobservables. Adding the ordered categorical structure produces more precise estimates. Both facts support the use of the full model (7). The comparison also indicates that the coresidence effect is unlikely to be substantially positive.

[Insert Table 10]

I also conduct a simple goodness-of-fit test. Using 4,000 Monte Carlo simulation draws of $\left(\theta, \varepsilon_{D}, \varepsilon_{0}, \varepsilon_{1}\right)$, I check to what extent the preferred model can correctly predict the coresidence status and health outcomes. The baseline specification is an independent combination of a binary probit for coresidence and a standard ordered probit for health outcomes. This baseline model correctly predicts $15.6 \%$ of the observed data, whereas the full model $(7)$ correctly predicts $15.8 \%$. Thus the factor structure model is able to reproduce the observed data fairly well.

\section{Why The Negative Coresidence Effect? The Theory of Health Transfer}

The negative coresidence effect on the treated may appear to contradict the widely accepted assumption that informal care is important and that coresiding children are caregivers who provide essential assistance to elderly parents. However, my results are not inconsistent with the existing literature, as the past findings have been quite mixed. Moreover, using the same econometric approach, Johar and Maruyama (2014) also find a substantial negative coresidence effect on the treated, in spite of three major differences from this study: (1) 
the data set is from Indonesia; (2) the parents and children used in the sample are younger; and (3) the identification relies on different instruments - traditions and customs.

In this section I propose a possible explanation based on the theory of demand for longevity as to why intergenerational coresidence may negatively affect parental health. I derive testable implications and test them by examining estimated marginal effects of covariates on the ATE.

\subsection{Theory of Health Transfer}

Coresidence with a child may or may not benefit parents. Coresidence entails not only informal healthcare but also domestic assistance, risk sharing, economy of scale, and (probably most important) companionship, comfort, and other mental and emotional benefits. Coresidence may also entail costs such as reduced privacy, loss of self-esteem, and conflicts in social relations. Similarly, coresidence may or may not benefit children. Children may benefit from housing, economies of scale, and additional time spent with parents. If parents have care needs, however, caregiving burdens reduce the utility of children in coresidence, as is widely documented (Fast et al., 1999; Hall et al., 2014). Despite the reduced utility due to physical and mental exertion and opportunity costs, children live with parents with care needs for various reasons, such as the consumption value of shared time, altruism, filial piety, social and cultural norms, and inheritance anticipation, but children will avoid coresidence if their expected lifetime utility loss exceeds a certain threshold.

In the meantime, a parent making health-related decisions takes into consideration their marginal benefits and costs. Health-related decisions cover various aspects of one's life, such as regular exercise, healthy diet, engaging in social activities, frequent medical 
checkups, and the search for good doctors, hospitals, and insurance plans. Such decisions affect the future trajectory of health over one's remaining years and thereby determine one's longevity.

The parent's problem is to optimally allocate her endowed resources, such as wealth, time, and effort, in order to maximize her expected lifetime utility. The parent's lifetime utility is an increasing function of her remaining years and the child's utility, if she has altruism toward her child. The child's expected lifetime net utility gain from coresidence is the per-period net utility gain from coresidence multiplied by the number of years that the parent is expected to live.

This structure creates a trade-off for the parent regarding longevity, which is the central idea of the theory. Although additional years of life increase the lifetime utility of the parent, when she has care needs and lives with her child, the child incurs a coresidence burden and this disutility of the child provides the parent with a disincentive to make health investments through the channels of altruism and exchange.

First, parental altruism is likely to reduce the marginal benefit of health investments, because the prolonged coresidence expected from health investments further burdens her child. Second, even if the parent is not altruistic, in order to maintain coresidence she must compensate the child (or "buy" coresidence) by providing financial transfers, by offering time-related services, or by shortening the remainder of her life. This "exchange channel" also lowers the marginal benefit of health investments because prolonging a life increases the implicit price of coresidence.

These disincentives to make health investments may generate a negative coresidence effect. If the expected lifetime utility gain from coresidence is sufficiently large, the parent 
may prefer to live with her child by sacrificing her life expectancy to lessen the child's burden.

The idea of a rational decision in regard to the trade-off between longevity and quality of life dates back to the health capital model proposed by Grossman (1972), in which individuals choose the utility-maximizing allocation of time and wealth, considering the marginal benefits and costs of health investments over the course of their lifetime, ultimately choosing the optimal date of death.

The literature on resource allocation within families also dates back to the 1970s. The studies by Barro (1974) and Becker (1974) show that altruistically linked families pool their resources, and public transfers across generations are neutralized by within-family transfers (the Ricardian equivalence). ${ }^{8}$ The literature has since discussed various parental motives behind the intergenerational financial transfers that parents make to their children in the form of bequests and inter vivos transfers. According to the exchange hypothesis, nonaltruistic parents may "buy" time-related services, such as informal care, by compensating their children's disutility with additional resource transfers (Bernheim et al., 1985; Cox, 1987). I contribute to this literature by emphasizing the role of parental health as a medium of intergenerational transfers.

\subsection{Testable Implications}

In the discussion so far, I have provided an explanation as to why elderly parents who live with their children may not "choose" longer lives, pointing out the trade-off in the

\footnotetext{
${ }^{8}$ Note that the term "altruism" here has no moral connotation. It simply means that an altruistic parent maximizes her utility "selfishly" by "consuming" her child's utility. The real motive may stem from enthusiastic love or moral responsibility associated with the parent's traditional sociocultural role.
} 
demand for longevity. If the parental decision is governed by altruism or an exchange motive, parents in coresidence have limited incentives to live for a long time. This theory serves as a possible explanation if we empirically observe a negative coresidence effect. In the rest of this section, using an informal comparative-statics argument, I derive testable implications that allow me to test the plausibility of the theory of health transfer.

Coresidence Burdens The parent's trade-off hinges on the child's utility cost, which is the per-period coresidence burden multiplied by the expected length of coresidence. This implies that a larger per-period burden will lead to a worse coresidence effect because of the larger marginal costs of additional years of life.

Prediction 1 All else equal, a larger per-period coresidence burden leads to a worse coresidence effect on parental health.

In reality, the per-period caregiving burden is not a constant; disability and care burdens increase over time, often together with a decline in health. Thus reduced health investments may increase these burdens, and parents may have a greater incentive to maintain their health, to reduce future burdens on children. Although this introduces ambiguity into the theoretical prediction of the coresidence effect, under mild assumptions, ${ }^{9}$ elderly parents with no care needs have a greater incentive than those with disabilities to remain healthy so that they can delay the outset of caregiving burdens, whereas a severe disability creates a disincentive to make health investments. Therefore, even if the per-period burden changes over time, a larger per-period burden is likely to lead to a worse coresidence effect.

\footnotetext{
${ }^{9}$ Theoretical predictions depend on the dynamic transition processes of health, disability, and caregiving utility costs.
} 
To test this prediction, I look at widowhood and disability as measured by activities of daily living. Once other health status variables are controlled for, these variables should capture the extent of the burden that coresidence imposes on children. Marital status matters because a spouse provides care and attention, often as the primary caregiver. If the estimated coresidence effect worsens with these coresidence burden measures, the data support the theory.

Opportunity Costs for Children By the same token, the health reduction is expected to increase with the child's opportunity cost. If the parent is altruistic, a reduction in the child's utility means a reduction in the parent's utility as well. Alternatively, a higher opportunity cost implies that the coresidence burden is more likely to exceed the child's tolerance threshold. In either case, when the child who provides care has other more important preoccupations, such as work opportunities in distant cities, the parent's incentive to make health investments is dampened.

Prediction 2 All else equal, the larger the per-period opportunity cost for the child, the greater the negative coresidence effect on parental health.

To test this prediction, because the data do not provide information on children's income or wages, I use (i) the age of the child, assuming that the opportunity cost is larger for younger children because compromise in their career development has a greater impact on their lifetime earnings than it does on those of older children; and (ii) the proportion of female children, assuming that the opportunity cost is smaller for daughters than for sons because their career opportunities are relatively limited (in Japan this discrepancy is particularly salient) and because women are more efficient than men when it comes to 
providing informal care.

Wealth The theoretical prediction regarding parental wealth is ambiguous. On one hand, instead of rewarding their children by means of health transfers, wealthy parents can do so by means of financial transfers (the King Lear effect in Bernheim et al., 1985). This is plausible because for elderly individuals the marginal utility of consumption is small relative to the marginal utility of life expectancy (Ehrlich and Chuma, 1990). Consequently, wealthy parents will not need to compromise their longevity and will enjoy a better coresidence effect.

On the other hand, a longer life eats up parental wealth and reduces the amount of bequest transfers. Children of wealthy parents can receive larger transfers if their parents die earlier (the Prince Hal situation in Goody, 1987). Hence the possible bequest transfers amplify the trade-off of altruistic parents, and the amount of parental wealth may be negatively correlated with the coresidence effect.

Because the data provide no direct measure of wealth, I examine how the coresidence effect varies with proxies for parental wealth: parents' education, housing asset, and income.

Bargaining If a family is not (strongly) altruistically linked, the number of children in the family affects the bargaining power of the parent. Specifically, parents with fewer children will have less bargaining power and will need to reduce their longevity to a greater extent. An only child has the greatest bargaining power and the parent faces the highest implicit price for coresidence. This hypothesis can be tested by the number of children.

Prediction 3 All else equal, when intergenerational family bargaining dominates family altruism, a parent with fewer children experiences a worse coresidence effect. 
Note that if a family is predominantly altruistically linked, Prediction 3 may not hold, but the theory can still explain a negative coresidence effect and Predictions 1 and 2 may still hold.

\subsection{Marginal Effects on $A T E$ and Testing Theory Predictions}

Not only unobservable but also observable characteristics generate heterogeneity in the coresidence effect. The relationship between the observables and the coresidence effect allows us to test the theory predictions and infer the mechanism underlying the coresidence effect. Table 11 reports the calculated marginal effects of the observed characteristics on the ATE. Parents who experience a worse coresidence effect tend to be widowed mothers who are afflicted with ADL limitations, depression-related symptoms, and dementia. They also tend to be not involved in household financial management and have younger sons. The marginal effects of observed characteristics can also be estimated for a model with no selection on unobservables (i.e. $\alpha_{0}=\alpha_{1}=0$ ). The marginal effects estimated with this restricted model show largely consistent magnitudes and significance, implying that the discussion in this subsection does not depend on the choice of my instruments.

\section{[Insert Table 11]}

Are these observations consistent with the theory's predictions? The first prediction, regarding the care burden, is supported by the significant, negative relationship between daily-activity limitations and the ATE. Although disability is closely related to the future health outcome in general, this negative relationship is observed even when the other baseline health characteristics are controlled for. In contrast, the subjective-health dummies and the cancer dummy indicate no significant impact on the ATE. These variables are 
more closely related to health and remaining years of life. What matters in regard to the consequences of coresidence is therefore the burden of caregiving on coresiding children, not parental health conditions. ${ }^{10}$ In addition, the estimated coefficient on Spouse also confirms the first prediction: widowed parents tend to experience a worse coresidence effect. The second prediction about the lifetime opportunity costs for the child is also supported by the positive coefficient on the child's age (where the parent's age is controlled for). The child's higher marginal utility of time provides the parent with a disincentive to make health investments. The positive and significant coefficient on the ratio of female children also supports the health-transfer theory, although this is also consistent with the widespread notion that women are better caregivers than men.

I find no definitive evidence that wealth has a protective effect. The estimates of income and working status are insignificant, perhaps because they are not suitable proxies for the wealth of the elderly: the house asset constitutes a large portion of their wealth especially in Japan. The estimated coefficient on house ownership has an expected sign, suggesting that those who own a house do not need to sacrifice their health, but its $t$-value is only 1.42. The variable income missing exhibits a negative and significant estimate, indicating that parents who did not provide their approximate income level in the survey may have very limited transferable wealth or limited control over family wealth. This is a finding consistent with the theory. Regarding the third prediction about family bargaining, the number of children is negative and significant. This finding contradicts the family-bargaining hypothesis and suggests that the negative coresidence effect is due to parental altruism.

\footnotetext{
${ }^{10}$ Like the ADL disability variable, the presence of depression and dementia (other contributors to the coresidence burden) has a negative effect on the ATE. The interpretation of this finding, however, is not straightforward, because it is unclear how much rational control parents afflicted with depression and dementia have over decisions related to their health.
} 
It is thus reasonable to conclude that elderly parents who tend to suffer from a substantial negative impact from coresidence are those who expect to rely significantly on their children without the means to make financial compensation as a quid pro quo.

Indirect support for the health-transfer hypothesis is also found in many Japanese survey studies. A survey of over 2,000 Japanese conducted in 2004 reveals that roughly $40 \%$ of respondents did not hope for a long life and that one of their chief concerns was not to impose burdens of caregiving on their families (Arai et al., 2005; Arai and Arai, 2008). As Long (2006) discusses, it is a widely accepted notion that an ideal death is a death that is peaceful, painless, and sudden, lest it impose caregiving burdens on others. Another survey based on the Japanese over 40 years of age, finds that more than $60 \%$ of the respondents prefer such sudden death and that one of the major reasons for this preference is to avoid imposing care burdens on their families (Kotani, 2004).

\subsection{Alternative Explanations}

Abuse and Neglect A negative coresidence effect is also consistent with abuse and neglect of elders. Nishi et al. (2010) find that Japanese women cared for by their daughtersin-law have a lower survival rate than those dependent on any other category of caregiver, and propose that abuse and neglect are the most likely cause. Lachs et al. (1998) report that elderly Americans who experienced abuse were 3.1 times more likely to die during a 3year period than those who were not mistreated, and in Japan, the majority of perpetrators are daughters-in-law (Soeda and Araki, 1999).

Although abuse and neglect are not uncommon in Japan and thus appear to be responsible for a part of the negative coresidence effect, they are unlikely to be the driving force 
behind the negative coresidence effect for the following reasons. First, if a child has a means to undermine parental health and chooses to do so, the expected return on such conduct should increase with the parent's wealth. In Japanese civil law, the decedent's next of kin have a legal right to a statutory fraction, or legitim, of the decedent's gross estate and cannot be disinherited. However, the signs of the estimated marginal effects of wealth-related variables in Table 11 are not consistent with this theoretical prediction. Second, such a bad relationship cannot explain the formation of coresidence. It is natural to assume that families make the coresidence decisions on the basis of the expected costs and benefits, and a good relationship should contribute to the benefit of coresidence. ${ }^{11}$ Third, although it is natural to presume that abuse and neglect are associated with the elderly parent's lower life satisfaction, the subjective happiness index shows no marginal effect on the $A T E$ in Table 11.

Exposure to Microbes and Viruses Coresidence may negatively affect parental health through a greater exposure to microbes and viruses. To determine whether this is the driving force behind the negative coresidence effect, I estimate a model to which I add another covariate, the proportion of children in bad health among all the siblings as a proxy for the coresiding child's health. ${ }^{12}$ This model yields an ATE and an ATT almost identical to those of the preferred model, and shows no relationship between the ATE and

\footnotetext{
${ }^{11}$ Undoubtedly certain families initiate coresidence on the basis of biased expectations or because they simply do not have other options, and daughters-in-law, particularly under Japanese virilocal traditions, may be forced to be the caregiver irrespective of their preferences. However, during my sample period, Japanese families are as mobile as those in other modern societies and exhibit a wide range of living arrangements, so it is reasonable to assume that the living arrangements observed in my data reflect the preferences of the families rather than traditions and social norms.

${ }^{12}$ In the NUJLSOA, a child is defined to be unhealthy if described by the parent as "not healthy enough to take care of someone".
} 
the health measure of children. ${ }^{13}$ Another rebuttal to this hypothesis is the fact that the presence of a spouse has no significant effect on the respondent's health on average (Table 5), whereas the hypothesis implies that married individuals are more likely to be exposed to viruses than are individuals living alone. Furthermore, the marginal effect of the presence of a spouse on the ATE is positive and highly significant (Table 11). ${ }^{14}$

Access to Care As shown in Table 4, parents living with children are on average poorer than parents living without children. One might therefore presume that because elderly parents in coresidence are on average poorer and cannot afford access to health and nursing care, an econometrician observes a spurious negative relationship between coresidence and future health. This explanation is unlikely, however, to be valid in the case of Japan. The Japanese health care system guarantees universal access, and during the sample years of this study, the out-of-pocket payments made by the elderly were quite small and the affordability of health and nursing care was not a major issue. ${ }^{15}$ In addition, because Japan introduced public long-term care insurance in April 2000, the affordability of basic nursing assistance was not a major issue either.

Note that, even if there were a significant income gradient regarding access to care, my empirical framework takes into account such baseline differences. The negative coresidence effect comes from comparison between those who live with children and those who live without children, controlling for selection on observables and unobservables. Income,

\footnotetext{
${ }^{13}$ The $z$-value of its marginal effect is -0.25 . The results are available upon request.

${ }^{14}$ One might argue that the reason for the non-negative effect of a spouse is that the effect of exposure to viruses is not greater than the protective effect of a spouse. If that is the case, however, this exposureto-viruses story is not a convincing explanation of the negative coresidence effect.

${ }^{15}$ For example, from September 1997 to December 2000, an outpatient visit cost elderly Japanese 500 Japanese yen (approximately 5 US dollars in early 2000), only up to the fourth visit, and from January 2001 to March 2008 they were charged a $10 \%$ copayment, only up to a certain small maximum amount. However, out-of-pocket payments have significantly increased since 2008.
} 
wealth, and education are included as control variables.

Data Issues: Institutional Care and Interview Proxy An alternative to coresidence and informal care is institutional care (e.g., nursing homes). Since institutional care is provided by medical professionals, it may be associated with better health outcomes. This fact may therefor induce a spurious negative coresidence effect. In the population of this study, however, the group of elderly parents living without children does not include those receiving institutional care.

Another possible explanation is that because elderly parents who live without children may eventually move to a nursing home once their health deteriorates, there may exist a positive selection in this group compared with those who live with children. However, such selection is not likely to be the driving force behind the negative coresidence effect. In Japan, institutional care has traditionally been for those who have no other choice. Nursing homes as a satisfactory alternative to coresidence are still under development in Japan and tend to be expensive. Few of the elderly parents surveyed in the NUJLSOA moved to a nursing home.

In the NUJLSOA, if a respondent is incapable of being interviewed, the interview may be conducted with a proxy, typically a family member in the household. This is another potential source of bias because seriously ill parents living alone are less likely to be observed in the data due to the absence of a proxy than are parents who are seriously ill but living with a child. Because this selection bias due to the lack of a proxy is relevant only in the case of parents living alone, I can confirm that this possibility is not a major concern by estimating the coresidence effect separately for married and unmarried parents (using the LPM and IV-LPM models in Table 5). In fact, the coresidence effect of married couples 
proves to be somewhat more negative that of unmarried couples, although the difference is not statistically significant.

\section{Conclusions}

Although intergenerational coresidence is declining, it is still the most common living arrangement in the world (UN, 2005), and many countries expect to rely on informal care from family members in the foreseeable future. In underdeveloped countries, approximately $75 \%$ of elderly persons live with a child. In European countries the average is about $25 \%$, but the trend toward solitary living has slowed or halted in many countries.

In this study I find a statistically significant, negative coresidence effect on the treated. Estimated heterogeneity in the treatment effect suggests that vulnerable parents with serious care needs but without the means to make financial compensation are most likely to be in coresidence and to suffer from a substantial negative impact of coresidence. These findings are consistent with the hypothesis that coresidence negatively affects parental health by creating disincentives for parents to invest in their health when there is no means to make financial compensation as a quid pro quo.

Four policy implications are worth mentioning. First, policies that aim to directly affect living arrangements need to be carefully designed. The Singaporean government, for example, has introduced housing tax incentives to promote intergenerational coresidence and to maintain the traditional social structure (Mehta et al., 1995). My results raise a concern that such policies may result in an unintended adverse effect on parental health. Second, my results highlight the importance of policies that not only reduce the burden of caregiving on coresiding children but also support the financial independence of the 
elderly so that they do not have to sacrifice their health. Third, for such policies to be effective, the intergenerational link needs to be taken into consideration because it may cause a version of the Ricardian equivalence. For example, when governments provide informal care support for altruistically linked families, especially those in coresidence, and finance its cost by taxing the younger generation, families may respond in such a way that their responses dilute the effect of the policy (the Ricardian neutralization). Fourth, the significant heterogeneity in the coresidence effect even after the introduction of the LongTerm Care Insurance in 2000 suggests potential scope for a better-targeted long-term care program in Japan. Further causal evidence is needed to understand the effectiveness of informal care and its determinants.

\section{References}

[1] Aakvik, A., Heckman, J.J., Vytlacil, E.J., 2005. Estimating treatment effects for discrete outcomes when responses to treatment vary: an application to Norwegian vocational rehabilitation programs. Journal of Econometrics 125, 15-51.

[2] Arai, A., Arai, Y., 2008. Advance care planning among the general public in Japan: association with awareness about dementia. Nippon Ronen Igakkai Zasshi (in Japanese) 45, 640-646.

[3] Arai, Y., Kumamoto, K., Zarit, S.H., Dennoh, H., Kitamoto, M., 2005. Angst in Shangri-La: Japanese fear of growing old. Journal of American Geriatrics Society $53(9), 1641-1642$.

[4] Banks, J., Smith, J.P., 2011. International comparisons in health economics: evidence 
from aging studies. RAND Working Paper, WR-880.

[5] Barro, R.J., 1974. Are government bonds net wealth? Journal of Political Economy 82(6), 1095-1117.

[6] Becker, G.S., 1974. A theory of social interactions. Journal of Political Economy 82, 1063-1093.

[7] Bernheim, B.D., Schleifer, A., Summers, L.H., 1985. The strategic bequest motive. Journal of Political Economy 93, 1045-1076.

[8] Carmichael, F., Charles, S., Hulme, C., 2010. Who will care? Employment participation and willingness to supply informal care. Journal of Health Economics 29, 182-190.

[9] Chan, A., Malhotra, C., Malhotra, R., Østbye, T., 2011. Living arrangements, social networks and depressive symptoms among older men and women in Singapore. International Journal of Geriatric Psychiatry 26(6), 630-639.

[10] Cox, D., 1987. Motives for private income transfers. Journal of Political Economy 95, 508-546.

[11] Davis, M.A., Moritz, D.J., Neuhaus, J.M., Barclay, J.D., Gee, L., 1997. Living arrangements, changes in living arrangements, and survival among community dwelling older adults. American Journal of Public Health 87(3), 371-377.

[12] Do, Y., Malhotra, C., 2012. The effect of coresidence with an adult child on depressive symptoms among older widowed women in South Korea: an instrumental variable estimation. Journal of Gerontology B: Psychological Sciences and Social Sciences 67B(3), 384-391. 
[13] Ehrlich, I., Chuma, H., 1990. A model of the demand for longevity and the value of life extension. Journal of Political Economy 98(4), 761-782.

[14] Ettner, S.L., 1995. The impact of "parent care" on female labor supply decisions. Demography 32(1), 63-80.

[15] Fast, J.E., Williamson, D.L., Keating, N.C., 1999. The hidden costs of informal elderly care. Journal of Family and Economic Issues, 20(3), 301-326.

[16] Fujino, Y., Matsuda, S., 2009. Prospective study of living arrangement by the ability to receive informal care and survival among Japanese elderly. Preventive Medicine 48, 79-85.

[17] Goody, J., 1987. Inheritance. The New Palgrave: A Dictionary of Economics. First Edition. Eds. Eatwell, J., Milgate, M., \& Newman, P. Palgrave Macmillan.

[18] Grossman, M., 1972. On the concept of health capital and the demand for health. Journal of Political Economy 80(2), 223-255.

[19] Hall, J., Kenny, P., Hossain, I., Street, D.J., Knox, S.A., 2014. Providing informal care in terminal illness: an analysis of preferences for support using a discrete choice experiment. Medical Decision Making 34(6), 731-745.

[20] Heitmueller, A., 2007. The chicken or the egg? Endogeneity in labour market participation of informal carers in England. Journal of Health Economics 26, 536-559.

[21] Hughes, M.E., Waite, L.J., 2002. Health in household context: living arrangements and health in late middle age. Journal of Health and Social Behavior 43, 1-21.

[22] Ikeda, A., Iso, H., Kawachi, I., Yamagishi, K., Inoue, M., Tsugane, S., 2009. Living arrangement and coronary heart disease: the JPHC study. Heart 95, 577-583. 
[23] Johar, M., Maruyama, S., 2014. Does coresidence improve an elderly parent's health? Journal of Applied Econometrics 29(6), 965-983.

[24] Johar, M., Maruyama, S., Nakamura, S., 2014. Reciprocity in the formation of intergenerational coresidence. Journal of Family and Economic Issues, forthcoming (article first published online: January 2014).

[25] Kenny, P.M., Hall, J.P., Zapart, S., Davis, P.R., 2010. Informal care and home-based palliative care: the health-related quality of life of carers. Journal of Pain and Symptom Management 40(1), 35-48.

[26] Kharicha, K., Iliffe, S., Harari, D., Swift, C., Gillmann, G., Stuck, A., 2007. Health risk appraisal in older people: are older people living alone an 'at-risk' group? British Journal of General Practice 57(537), 271-276.

[27] Kotani, M., 2004. Shi ni taisuru ishiki to shi no osore (in Japanese). Life Design Report, May, Dai-ichi Life Research Institute Inc.

[28] Lachs, M.S., Williams, C.S., O’Brien, S., Pillemer, K.A., Charlson, M.E., 1998. The mortality of elder mistreatment. Journal of the American Medical Association 280, 428-432.

[29] Li, L.W., Zhang, J., Liang, J., 2009. Health among the oldest-old in China: which living arrangements make a difference? Social Science \&3 Medicine 68, 220-227.

[30] Long, S.O., 2006. Final Days: Japanese Culture and Choice at the End of Life. University of Hawaii Press. ISBN 978-0824829643.

[31] Lund, T., Due, P., Modvig, J., Holsetin, B.E., Damsgaard, M.T., Andersen, P.K., 2002. Cohabitation and marital status as predictors of mortality — an eight year 
follow-up study. Social Science \& Medicine 55, 673-679.

[32] Maruyama, S., Johar, M., 2013. Do siblings free-ride in 'being there' for parents? UNSW Australian School of Business Research Paper, No. 2013 ECON 06, University of New South Wales.

[33] Mehta, K., Osman, M.M., Lee E.Y., A., 1995. Living arrangements of the elderly in Singapore: cultural norms in transition. Journal of Cross-Cultural Gerontology 10, 113-143.

[34] Michael, Y.L., Berkman, L.F., Colditz, G.A., Kawachi, I., 2001. Living arrangements, social integration, and change in functional health status. American Journal of Epidemiology 153(2), 123-131.

[35] Ministry of Health, Labour and Welfare, 2008. Report on the Comprehensive Survey of Living Conditions of the People on Health and Welfare (In Japanese). Available at: http://www.mhlw.go.jp/toukei/list/20-19-1.html.

[36] Nishi, A., Tamiya, N., Kashiwagi, M., Takahashi, H., Sato, M., Kawachi, I., 2010. Mothers and daughters-in-law: a prospective study of informal care-giving arrangements and survival in Japan. BMC Geriatrics 10:61.

[37] OECD, 2005. The OECD Health Project: Long-Term Care for Older People. OECD, Paris.

[38] OECD, 2013. A Good Life in Old Age? Monitoring and Improving Quality in Longterm Care. OECD, Paris.

[39] Rogers, R.G., Hummer, R.A., Nam, C.B., 2000. Living and Dying in the USA; Behavioral, Health and Social Differentials of Adult Mortality. San Diego, CA: Academic 
Press.

[40] Russell, D., Taylor, J., 2009. Living alone and depressive symptoms: the influence of gender, physical disability, and social support among Hispanic and non-Hispanic older adults. Journal of Gerontology: Social Sciences 64B(1), 95-104.

[41] Silverstein, M., Cong, Z., Li, S., 2006. Intergenerational transfers and living arrangements of older people in rural China: consequences for psychological well-being. Journal of Gerontology: Social Sciences 61B(5), S256-S266.

[42] Soeda, A., Araki, C., 1999. Elder abuse by daughters-in-law in Japan. Journal of Elder Abuse and Neglect 11, 47-58.

[43] Stock, J.H., Yogo, M., 2005. Testing for weak instruments in linear IV regression. In Identification and Inference for Econometric Models: Essays in Honor of Thomas Rothenberg, ed. Andrews, D.W.K., \& Stock, J.H., 80-108. Cambridge University Press.

[44] Sugawara, S., Nakamura, J., 2014. Can formal elderly care stimulate female labor supply? The Japanese experience. Journal of The Japanese and International Economies 34, 98-115.

[45] Tabuchi, R., 2008. Parental housing assistance as a determinant of parentchild proximity in Japan: Results from the JGSS-2006. Japanese General Social Surveys Research Series 7, 13-23 (in Japanese). http://jgss.daishodai.ac.jp/research/monographs/jgssm7/jgssm7_02.pdf.

[46] United Nations, 2005. Living Arrangements of Older Persons around the World. Department of Economic and Social Affairs, Population Division, United Nations. 
[47] Walter-Ginzburg, A., Blumstein, T., Chetrit, A., Modan, B., 2002. Social factors and mortality in the old-old in Israel: the CALAS study. Journal of Gerontology: Social Sciences 57B(5), S308-318.

[48] Wang, D., Zheng, J., Kurosawa, M., Inaba, Y., Kato, N., 2009. Changes in activities of daily living (ADL) among elderly Chinese by marital status, living arrangement, and availability of healthcare over a 3-year period. Environmental Health and Preventive Medicine 14, 128-141. 


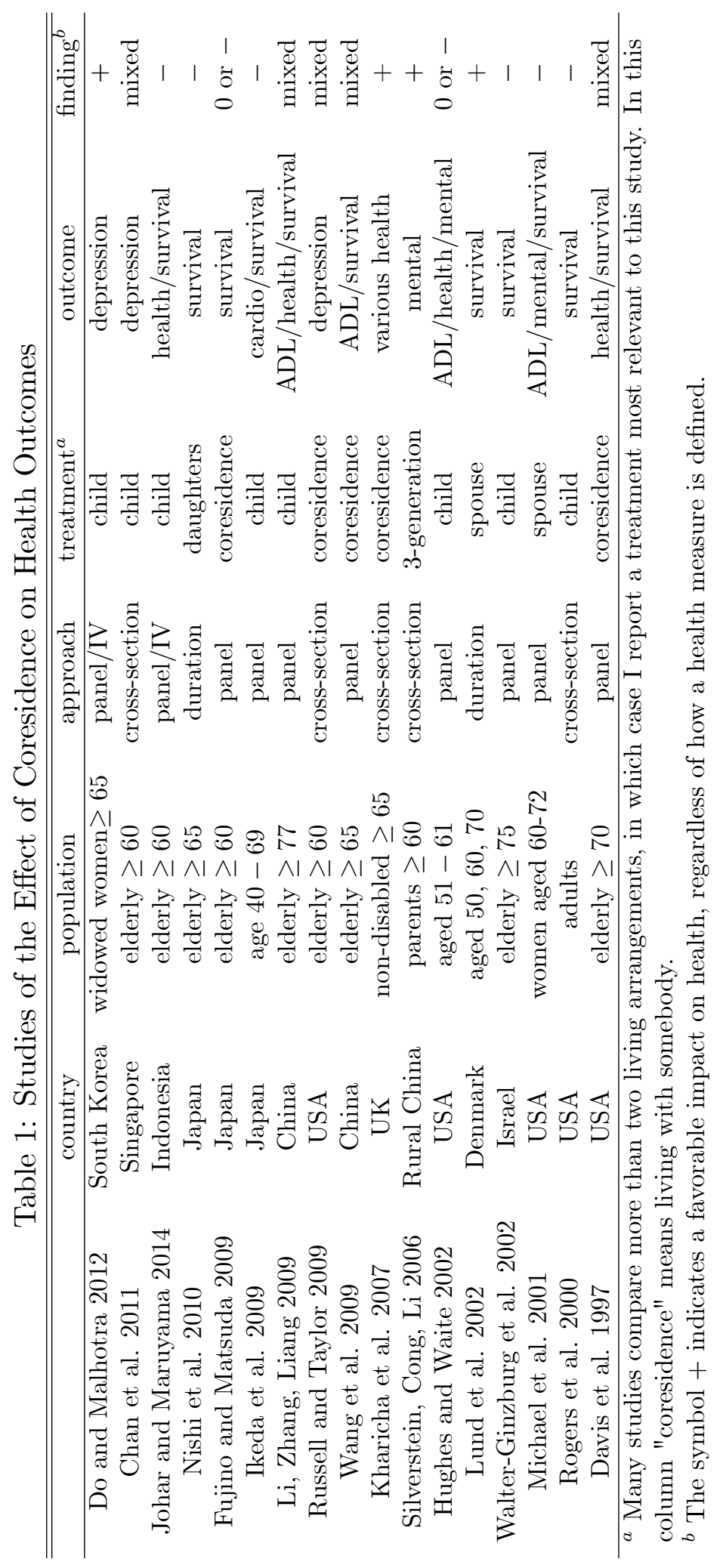


Table 2: Definitions of Variables

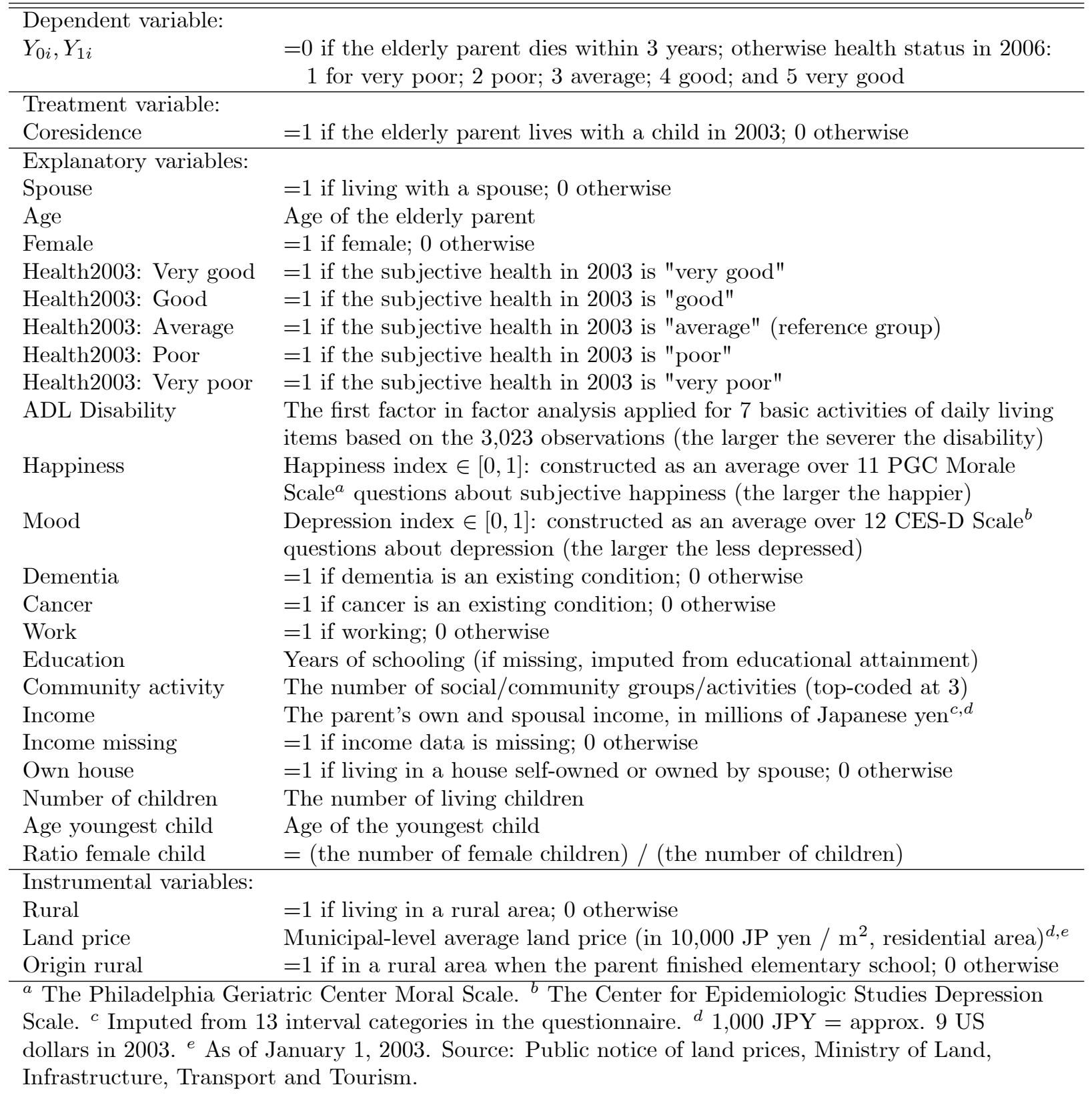


Table 3: Distribution of Health Outcomes after Three Years and Baseline Health

\begin{tabular}{lrrrrrr}
\hline \hline & All parents & \multicolumn{4}{c}{ Coresidence status in 2003 } \\
\cline { 3 - 7 } & & & \multicolumn{2}{c}{ Non-coresidence } & \multicolumn{3}{c}{ Coresidence } \\
\hline Total & 3,023 & $(100 \%)$ & 1,451 & $(100 \%)$ & 1,572 & $(100 \%)$ \\
\hline$Y_{i}$ : health outcomes $(2006)$ & & & & & \\
5: Very good & 322 & $(10.7 \%)$ & 159 & $(11.0 \%)$ & 163 & $(10.4 \%)$ \\
4: Good & 474 & $(15.7 \%)$ & 220 & $(15.2 \%)$ & 254 & $(16.2 \%)$ \\
3: Average & 1,090 & $(36.1 \%)$ & 546 & $(37.6 \%)$ & 544 & $(34.6 \%)$ \\
2: Poor & 672 & $(22.2 \%)$ & 327 & $(22.5 \%)$ & 345 & $(22.0 \%)$ \\
1: Very poor & 163 & $(5.4 \%)$ & 81 & $(5.6 \%)$ & 82 & $(5.2 \%)$ \\
0: Dead & 302 & $(10.0 \%)$ & 118 & $(8.1 \%)$ & 184 & $(11.7 \%)$ \\
\hline Baseline health $(2003)$ & & & & & & \\
Very good & 429 & $(14.2 \%)$ & 226 & $(15.6 \%)$ & 203 & $(12.9 \%)$ \\
Good & 545 & $(18.0 \%)$ & 257 & $(17.7 \%)$ & 288 & $(18.3 \%)$ \\
Average & 1,251 & $(41.4 \%)$ & 601 & $(41.4 \%)$ & 650 & $(41.4 \%)$ \\
Poor & 675 & $(22.3 \%)$ & 308 & $(21.2 \%)$ & 367 & $(23.4 \%)$ \\
Very poor & 123 & $(4.1 \%)$ & 59 & $(4.1 \%)$ & 64 & $(4.1 \%)$ \\
\hline
\end{tabular}

Table 4: Means and Standard Deviations of Variables

\begin{tabular}{|c|c|c|c|c|c|c|}
\hline & \multicolumn{2}{|c|}{3,023 elderly parents } & \multicolumn{2}{|c|}{$\begin{array}{r}1,451 \text { parents living } \\
\text { without children }\end{array}$} & \multicolumn{2}{|c|}{$\begin{array}{r}1,572 \text { parents living } \\
\text { with a child }\end{array}$} \\
\hline & Means & Std. dev. & Means & Std. dev. & Means & Std. dev. \\
\hline Spouse & 0.64 & 0.48 & 0.75 & 0.43 & 0.55 & 0.50 \\
\hline Age & 75.36 & 7.03 & 74.38 & 6.58 & 76.27 & 7.32 \\
\hline Female & 0.54 & 0.50 & 0.49 & 0.50 & 0.59 & 0.49 \\
\hline Health2003: Very good & 0.14 & 0.35 & 0.16 & 0.36 & 0.13 & 0.34 \\
\hline Health2003: Good & 0.18 & 0.38 & 0.18 & 0.38 & 0.18 & 0.39 \\
\hline Health2003: Poor & 0.22 & 0.42 & 0.21 & 0.41 & 0.23 & 0.42 \\
\hline Health2003: Very poor & 0.04 & 0.20 & 0.04 & 0.20 & 0.04 & 0.20 \\
\hline ADL Disability & 0.00 & 0.98 & -0.11 & 0.59 & 0.10 & 1.22 \\
\hline Happiness & 0.73 & 0.22 & 0.74 & 0.22 & 0.72 & 0.21 \\
\hline Mood & 0.74 & 0.13 & 0.75 & 0.13 & 0.73 & 0.14 \\
\hline Dementia & 0.04 & 0.20 & 0.02 & 0.13 & 0.07 & 0.25 \\
\hline Cancer & 0.03 & 0.17 & 0.03 & 0.18 & 0.03 & 0.17 \\
\hline Work & 0.23 & 0.42 & 0.23 & 0.42 & 0.22 & 0.42 \\
\hline Education & 9.53 & 2.60 & 9.96 & 2.71 & 9.15 & 2.43 \\
\hline Community activity & 1.12 & 1.06 & 1.16 & 1.07 & 1.09 & 1.05 \\
\hline Income & 2.57 & 2.02 & 2.88 & 2.08 & 2.27 & 1.92 \\
\hline Income missing & 0.18 & 0.39 & 0.16 & 0.37 & 0.20 & 0.40 \\
\hline Own house & 0.72 & 0.45 & 0.82 & 0.39 & 0.64 & 0.48 \\
\hline Number of children & 2.46 & 1.06 & 2.30 & 0.98 & 2.61 & 1.12 \\
\hline Age youngest child & 43.93 & 7.64 & 43.05 & 7.04 & 44.74 & 8.07 \\
\hline Ratio female child & 0.48 & 0.35 & 0.48 & 0.36 & 0.47 & 0.33 \\
\hline Rural & 0.38 & 0.48 & 0.31 & 0.46 & 0.44 & 0.50 \\
\hline Land price & 10.67 & 11.52 & 11.87 & 12.80 & 9.56 & 10.07 \\
\hline Origin rural & 0.61 & 0.49 & 0.54 & 0.50 & 0.67 & 0.47 \\
\hline
\end{tabular}


Table 5: Linear Regressions of 3-Year Survival

\begin{tabular}{|c|c|c|c|c|c|c|c|c|c|}
\hline \multirow{2}{*}{$\begin{array}{c}\text { Dependent variable: } \\
\text { 3-year survival }\end{array}$} & \multicolumn{3}{|c|}{ Mean difference } & \multicolumn{3}{|c|}{$\overline{\text { LPM }}$} & \multicolumn{3}{|c|}{ IV-LPM $^{a}$} \\
\hline & Coeffic & & $t$-value & Coeffici & ient & $t$-value & Coeffic & ent & $t$-value \\
\hline Coresidence & -0.036 & $* * *$ & -3.30 & -0.002 & & -0.18 & -0.015 & & -0.19 \\
\hline Spouse & & & & -0.000 & & -0.02 & -0.002 & & -0.12 \\
\hline Age & & & & -0.010 & *** & -6.29 & -0.010 & $* * *$ & -6.28 \\
\hline Female & & & & 0.038 & $* * *$ & 3.42 & 0.038 & $* * *$ & 3.44 \\
\hline Health2003: Very good & & & & -0.000 & & -0.01 & -0.000 & & -0.01 \\
\hline Health2003: Good & & & & -0.003 & & -0.25 & -0.003 & & -0.22 \\
\hline Health2003: Poor & & & & -0.024 & & -1.56 & -0.024 & & -1.57 \\
\hline Health2003: Very poor & & & & -0.078 & $*$ & -1.76 & -0.079 & * & -1.73 \\
\hline ADL Disability & & & & -0.056 & *** & -5.39 & -0.056 & $* * *$ & -5.18 \\
\hline Happiness & & & & 0.001 & & 0.04 & 0.002 & & 0.07 \\
\hline Mood & & & & 0.132 & ** & 2.43 & 0.131 & $* *$ & 2.42 \\
\hline Dementia & & & & -0.092 & ** & -1.97 & -0.090 & $*$ & -1.87 \\
\hline Cancer & & & & -0.047 & & -1.31 & -0.047 & & -1.31 \\
\hline Work & & & & 0.007 & & 0.65 & 0.007 & & 0.64 \\
\hline Education & & & & 0.002 & & 0.90 & 0.002 & & 0.74 \\
\hline Community activity & & & & 0.010 & ** & 2.19 & 0.011 & $* *$ & 2.21 \\
\hline Income & & & & -0.000 & & -0.20 & -0.001 & & -0.26 \\
\hline Income missing & & & & -0.016 & & -1.18 & -0.015 & & -1.11 \\
\hline Own house & & & & -0.013 & & -0.99 & -0.014 & & -0.90 \\
\hline Number of children & & & & -0.004 & & -0.63 & -0.003 & & -0.47 \\
\hline Age youngest child & & & & 0.000 & & 0.34 & 0.000 & & 0.31 \\
\hline Ratio female child & & & & -0.004 & & -0.63 & -0.004 & & -0.28 \\
\hline Constant & 0.919 & **** & 127.99 & 1.491 & **** & 16.13 & 1.500 & **** & 13.89 \\
\hline$R^{2}$ & & 0.003 & & & $0.175 !$ & & & .175 & \\
\hline
\end{tabular}

Note: $N=3,023$. LPM stands for linear probability model. White's robust standard errors are used. ${ }^{*} \mathrm{p}<0.1,{ }^{* *} \mathrm{p}<0.05,{ }^{* * *} \mathrm{p}<0.01$.

${ }^{a}$ Three instruments, Rural, Land price, and Origin rural are applied to Coresidence.

They are significant in the first stage with $t$-statistics of $3.37,-2.38$, and 3.05 , respectively. 
Table 6: Instrument Validity Test Using Childless Parents

\begin{tabular}{|c|c|c|c|c|c|c|}
\hline \multirow[t]{2}{*}{ Dependent variable: } & \multicolumn{3}{|c|}{ 3-year survival (LPM) } & \multicolumn{3}{|c|}{ health outcome (ordered probit) } \\
\hline & Coeffic & & $t$-value & Coefficie & & $z$-value \\
\hline Spouse & -0.002 & & -0.05 & 0.003 & & 0.03 \\
\hline Age & -0.009 & *** & -3.11 & -0.025 & *** & -2.71 \\
\hline Female & 0.063 & & 1.49 & 0.092 & & 0.65 \\
\hline Health2003: Very good & -0.016 & & -0.29 & 0.615 & $* * *$ & 3.20 \\
\hline Health2003: Good & 0.026 & & 0.50 & 0.484 & *** & 2.79 \\
\hline Health2003: Poor & -0.054 & & -1.23 & -0.463 & *** & -3.16 \\
\hline Health2003: Very poor & -0.200 & ** & -2.47 & -0.728 & *** & -2.59 \\
\hline ADL Disability & -0.052 & ** & -2.07 & -0.238 & ** & -2.53 \\
\hline Happiness & -0.030 & & -0.30 & 0.415 & & 1.25 \\
\hline Mood & 0.302 & * & 1.88 & 0.788 & & 1.46 \\
\hline Dementia & -0.159 & * & -1.82 & -0.467 & & -1.57 \\
\hline Cancer & -0.010 & & -0.10 & -0.358 & & -1.05 \\
\hline Work & 0.023 & & 0.48 & 0.146 & & 0.91 \\
\hline Education & -0.000 & & -0.01 & 0.015 & & 0.72 \\
\hline Community activity & -0.014 & & -0.77 & 0.053 & & 0.90 \\
\hline Income & -0.011 & & -0.94 & -0.035 & & -0.89 \\
\hline Income missing & -0.059 & & -1.26 & -0.044 & & -0.28 \\
\hline Own house & 0.027 & & 0.71 & 0.004 & & 0.03 \\
\hline Rural & -0.013 & & -0.30 & 0.055 & & 0.39 \\
\hline Land price & 0.001 & & 1.15 & 0.003 & & 1.01 \\
\hline Origin rural & 0.025 & & 0.66 & -0.006 & & -0.05 \\
\hline Constant & 1.308 & *** & 5.44 & & & \\
\hline
\end{tabular}

Note: $N=379$. LPM stands for linear probability model. For the ordered probit model, the five cutoff points are estimated as $-2.21,-1.91,-1.01,0.26$, and 0.80 . ${ }^{*} \mathrm{p}<0.1,{ }^{* *} \mathrm{p}<0.05,{ }^{* * *} \mathrm{p}<0.01$. 
Table 7: Coresidence Equation

\begin{tabular}{l|rrrr}
\hline \hline & \multicolumn{2}{|c}{ Coefficient } & $z$-value & Marginal Effects $^{a}$ \\
\hline Spouse & -0.569 & $* * *$ & -6.97 & -0.146 \\
Age & 0.007 & & 0.79 & 0.002 \\
Female & 0.055 & & 0.76 & 0.014 \\
Health2003: Very good & -0.003 & & -0.03 & -0.001 \\
Health2003: Good & 0.090 & & 1.02 & 0.023 \\
Health2003: Poor & 0.004 & & 0.47 & 0.001 \\
Health2003: Very poor & -0.453 & $* *$ & -2.40 & -0.117 \\
ADL Disability & 0.153 & $* * *$ & 3.34 & 0.039 \\
Happiness & 0.350 & $*$ & 1.80 & 0.090 \\
Mood & -0.272 & & -0.85 & -0.070 \\
Dementia & 0.762 & $* * *$ & 3.46 & 0.196 \\
Cancer & 0.043 & & 0.24 & 0.011 \\
Work & 0.157 & $* *$ & 2.00 & 0.040 \\
Education & -0.025 & $*$ & -1.79 & -0.006 \\
Community activity & -0.014 & & -0.46 & -0.003 \\
Income & -0.024 & & -1.39 & -0.006 \\
Income missing & 0.257 & $* * *$ & 3.08 & 0.066 \\
Own house & -0.520 & $* * *$ & -6.51 & -0.134 \\
Number of children & 0.126 & $* * *$ & 3.82 & 0.033 \\
Age youngest child & -0.009 & & -1.16 & -0.002 \\
Ratio female child & -0.137 & & -1.51 & -0.035 \\
Rural & 0.187 & $* * *$ & 2.74 & 0.048 \\
Land price & -0.007 & $* *$ & -2.53 & 0.002 \\
Origin rural & 0.139 & $* *$ & 2.11 & 0.128 \\
Constant & 0.498 & & 0.91 &
\end{tabular}

${ }^{a}$ Defined as the analytical derivative averaged over the entire sample: $(1 / N) \sum_{i=1}^{N}\left[\int\left(\partial \operatorname{Pr}(D=1 \mid Z=z, \theta) / \partial z_{k}\right) \phi(\theta) d \theta\right]$. $* \mathrm{p}<0.1, * * \mathrm{p}<0.05, * * * \mathrm{p}<0.01$. 
Table 8: Health Outcome Equations

\begin{tabular}{|c|c|c|c|c|c|c|c|c|}
\hline & \multicolumn{4}{|c|}{ Non-coresidence outcome: $Y_{0}$} & \multicolumn{4}{|c|}{ Coresidence outcome: $Y_{1}$} \\
\hline & \multicolumn{2}{|c|}{ Coefficient } & \multirow{2}{*}{$\begin{array}{r}z \text {-value } \\
12.627\end{array}$} & \multirow{2}{*}{$\begin{array}{r}\text { M.E. }^{a} \\
0.077\end{array}$} & \multicolumn{2}{|c|}{ Coefficient } & \multirow{2}{*}{$\begin{array}{c}z \text {-value } \\
-12.85\end{array}$} & \multirow{2}{*}{$\begin{array}{r}\text { M.E. }^{a} \\
-0.088\end{array}$} \\
\hline Factor $(\theta)$ & 5.107 & $* * *$ & & & -5.282 & $* * *$ & & \\
\hline Spouse & -0.935 & $* * *$ & -3.02 & -0.014 & 0.679 & $* *$ & 2.31 & 0.011 \\
\hline Age & -0.084 & $* * *$ & -2.80 & -0.001 & -0.155 & $* * *$ & -5.21 & -0.003 \\
\hline Female & 1.200 & $* * *$ & 4.42 & 0.018 & 0.003 & & 0.01 & 0.000 \\
\hline Health2003: Very good & 3.630 & $* * *$ & 8.91 & 0.055 & 2.877 & $* * *$ & 7.41 & 0.048 \\
\hline Health2003: Good & 1.775 & $* * *$ & 5.07 & 0.027 & 1.299 & $* * *$ & 4.10 & 0.022 \\
\hline Health2003: Poor & -2.071 & $* * *$ & -6.16 & -0.031 & -2.254 & $* * *$ & -6.99 & -0.038 \\
\hline Health2003: Very poor & -3.712 & $* * *$ & -5.84 & -0.056 & -2.591 & $* * *$ & -4.13 & -0.043 \\
\hline ADL Disability & 0.030 & & 0.19 & 0.000 & -0.922 & $* * *$ & -7.81 & -0.015 \\
\hline Happiness & 2.075 & $* * *$ & 2.98 & 0.031 & 1.630 & $* *$ & 2.29 & 0.027 \\
\hline Mood & 1.121 & & 1.06 & 0.017 & 5.111 & $* * *$ & 4.47 & 0.085 \\
\hline Dementia & 0.856 & & 1.14 & 0.013 & -1.332 & $* * *$ & -2.65 & -0.022 \\
\hline Cancer & -1.063 & & -1.92 & -0.016 & -0.828 & & -1.10 & -0.014 \\
\hline Work & 0.955 & $* * *$ & 3.36 & 0.014 & 0.166 & & 0.58 & 0.003 \\
\hline Education & 0.025 & & 0.55 & 0.000 & 0.110 & $* *$ & 2.12 & 0.002 \\
\hline Community activity & 0.307 & $* * *$ & 2.78 & 0.005 & 0.179 & $*$ & 1.66 & 0.003 \\
\hline Income & 0.030 & & 0.43 & 0.000 & -0.006 & & -0.09 & -0.000 \\
\hline Income missing & 0.487 & $*$ & 1.69 & 0.007 & -0.904 & $* * *$ & -3.42 & -0.015 \\
\hline Own house & -0.784 & $* *$ & -2.55 & -0.012 & -0.015 & & -0.06 & -0.000 \\
\hline Number of children & 0.159 & & 1.42 & 0.002 & -0.250 & $* *$ & -2.41 & -0.004 \\
\hline Age youngest child & -0.049 & $*$ & -1.89 & -0.001 & 0.027 & & 1.20 & 0.000 \\
\hline Ratio female child & -0.573 & $*$ & -1.88 & -0.009 & 0.448 & & 1.40 & 0.007 \\
\hline Constant & 15.555 & $* * *$ & 7.01 & 0.235 & 14.632 & $* * *$ & 6.47 & 0.244 \\
\hline \multicolumn{9}{|l|}{ Cutoff parameters: } \\
\hline$c_{1}$ & 1.542 & $* * *$ & 9.19 & & & & & \\
\hline$c_{2}$ & 5.702 & $* * *$ & 12.90 & & & & & \\
\hline$c_{3}$ & 10.807 & $* * *$ & 13.57 & & & & & \\
\hline$c_{4}$ & 13.935 & $* * *$ & 13.48 & & & & & \\
\hline
\end{tabular}

${ }^{a}$ M.E. denotes marginal effects, defined as the analytical derivative averaged over the entire sample. For $Y_{j}, j=0,1:(1 / N) \sum_{i=1}^{N}\left[\int\left(\partial \operatorname{Pr}\left(Y_{j} \geq 1 \mid X=x, \theta\right) / \partial x_{k}\right) \phi(\theta) d \theta\right]$.

$* \mathrm{p}<0.1,{ }^{* *} \mathrm{p}<0.05,{ }^{* * *} \mathrm{p}<0.01$.

Table 9: Mean and Distributional Treatment Parameters on 3-Year Survival

\begin{tabular}{lr}
\hline \hline$A T E$ (average treatment effect): $(1 / N) \sum_{i=1}^{N}\left[\int \Delta^{A T E}(x, \theta) \phi(\theta) d \theta\right]$ & -0.0184 \\
standard error ${ }^{a}$ & 0.0133 \\
\hline Distributional version of $A T E$ & 0.041 \\
$\operatorname{Pr}(\Delta=1)$ & 0.899 \\
$\operatorname{Pr}(\Delta=0)$ & 0.060 \\
$\operatorname{Pr}(\Delta=-1)$ & -0.0532 \\
\hline$A T T$ (average treatment effect on the treated): $(1 / N) \sum_{i=1}^{N}\left[\int \Delta^{A T T}(D=1, x, z, \theta) \phi(\theta) d \theta\right]$ & 0.0086 \\
standard error ${ }^{a}$ & 0.0349 \\
$A T U$ (average treatment effect on the untreated): $(1 / N) \sum_{i=1}^{N}\left[\int \Delta^{A T U}(D=0, x, z, \theta) \phi(\theta) d \theta\right]$ & 0.0071 \\
$\quad$ standard error ${ }^{a}$ & \\
\hline a Standard errors are computed using the delta method for given $(x, \theta)$ and averaged over the sample.
\end{tabular}


Table 10: Average Treatment Parameters on 3-Year Survival from Different Methods

\begin{tabular}{|c|c|c|}
\hline & $A T E$ & Standard errors \\
\hline (1) Unconditional mean differences ${ }^{a}$ & -0.0357 & 0.0108 \\
\hline (2) Linear probability model with constant treatment effect ${ }^{b}$ & -0.0018 & 0.0103 \\
\hline (3) Linear IV constant treatment effect ${ }^{c}$ & -0.0152 & 0.0911 \\
\hline (4) Binary model without selection on unobservables ${ }^{d, e}$ & 0.0011 & 0.0508 \\
\hline (5) Binary model with selection on unobservables ${ }^{d}$ & -0.0064 & 0.0736 \\
\hline (6) Ordered model without selection on unobservables ${ }^{e}$ & 0.0038 & 0.0290 \\
\hline (7) Ordered model with selection on unobservables & -0.0184 & 0.0133 \\
\hline
\end{tabular}

${ }^{a} \widehat{E}\left(Y_{1} \mid D=1\right)-\widehat{E}\left(Y_{0} \mid D=0\right)$

${ }^{b}$ Based on an LPM form and the constant treatment assumption $(Y=X \beta+\gamma D+U)$.

${ }^{c}$ Linear estimation for the above LPM using the instruments.

${ }^{d}$ The dependent variable $Y=1$ if a parent survives and 0 otherwise.

${ }^{e}$ No selection on unobservables imposed, i.e., $\alpha_{0}=\alpha_{1}=0$.

Table 11: Marginal Effects of Covariates on Average Treatment Effect

\begin{tabular}{lrlr}
\hline \hline & Marginal effects on $A T E^{a}$ & \multicolumn{1}{c}{$z$-value } \\
\hline Spouse & 0.0254 & $* *$ & 2.56 \\
Age & -0.0013 & & -1.06 \\
Female & -0.0181 & $* *$ & -1.98 \\
Health2003: Very good & -0.0069 & & -0.25 \\
Health2003: Good & -0.0052 & & -0.35 \\
Health2003: Poor & -0.0062 & & -0.33 \\
Health2003: Very poor & 0.0129 & & 0.44 \\
ADL Disability & -0.0158 & $* *$ & -2.56 \\
Happiness & -0.0042 & $*$ & -0.18 \\
Mood & 0.0682 & $*$ & 1.68 \\
Dementia & -0.0351 & $* *$ & -1.96 \\
Cancer & 0.0023 & & 0.12 \\
Work & -0.0117 & & -1.31 \\
Education & 0.0015 & & 1.05 \\
Community activity & -0.0017 & & -0.50 \\
Income & -0.0006 & & -0.33 \\
Income missing & -0.0224 & $* * *$ & -2.47 \\
Own house & 0.0116 & & 1.42 \\
Number of children & -0.0066 & $* *$ & -2.07 \\
Age youngest child & 0.0012 & $*$ & 1.78 \\
Ratio female child & 0.0161 & $*$ & 1.82 \\
\hline
\end{tabular}

${ }^{a}$ The marginal effects, $E_{X, \theta}\left[\left(\partial \Delta^{A T E}(X=x, \theta) / \partial x_{k}\right)\right]$, are obtained by using the analytical derivative averaged over the sample:

$$
\begin{aligned}
& (1 / N) \sum_{i=1}^{N}\left[\int\left(\partial \Delta^{A T E}(X=x, \theta) / \partial x_{k}\right) \phi(\theta) d \theta\right] . \\
& * \mathrm{p}<0.1,{ }^{* *} \mathrm{p}<0.05, * * * \mathrm{p}<0.01 .
\end{aligned}
$$

